Zylberglait Lisigurski et al. HCA Healthcare Journal of Medicine (2021) 2:1

https://doi.org/10.36518/2689-0216.1074

\title{
Education
}

\section{Physicians' Emotional Intelligence: Improving Performance While Reducing Burnout}

Miriam Zylberglait Lisigurski, MD, FACP,' Umair Shaikh, MD, Brian Toston, DO'

\section{Abstract}

\section{Description}

Today's physicians are being confronted with an increasing number of challenges and opportunities as our evolving healthcare system progresses into the future. The expectation is not only to provide the best clinical care, but also to satisfy metrics, fulfill budgets, achieve high patient satisfaction levels and accomplish institutional requirements in order to be considered good providers. All these additional demands seem to be affecting not only the clinical performance of physicians but also their wellness, increasing the risk of burnout, depression and suicide.

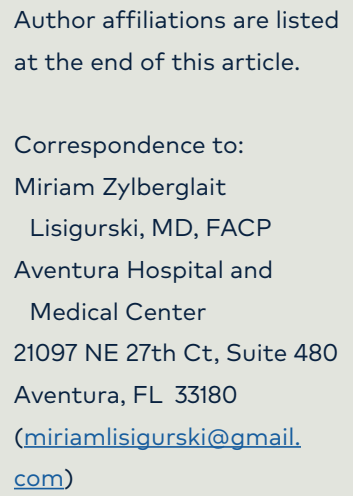

Keywords

emotional intelligence; professional burnout; physician performance; internship and residency; medical faculty; physicians/psychology; SARS-CoV-2

\section{Introduction}

Today's physicians are being confronted with an increasing number of challenges and opportunities as our evolving healthcare system progresses into the future. The expectation is not only to provide the best clinical care, but also to satisfy metrics, fulfill budgets, achieve high patient satisfaction levels and accomplish institutional requirements in order to be considered good providers. All these additional demands seem to be affecting not only the clinical performance of physicians but also their wellness, ${ }^{1,2}$ increasing the risk of burnout, depression and suicide. ${ }^{3}$

While the practice of medicine was already challenging, COVID-19 intensified the gaps and the exigencies, adding more stressors to clinicians, health workers and the entire healthcare system. ${ }^{4,5,6,7}$ Physicians and other health professionals have been confronting this unprecedented crisis while having limited resources, increased workload and longer hours. ${ }^{4,5,6,7}$ The emotional component of dealing with severely sick people, frequent death and challenging ethical decisions have added additional stressors. This emotionally and physically demanding situation is being exacerbated by the disruptions in their work-life balance, the need of being isolated from their own families and the fear of being infected by the virus. ${ }^{4,5,6,7}$

This complex and unexpected panorama is exposing the gaps in our health system but also in medical training. ${ }^{8}$ Now it seems more evident than ever that exceptional medical knowledge and clinical skills are not enough to be considered a proficient physician ${ }^{9}$ since neither accomplishment grants the ability to deal with crisis situations without sacrificing the physician's own wellbeing.

Despite this new reality, we need to find alternatives that will allow health care professionals to keep performing at their maximum level while maintaining their wellbeing. There is increasing data suggesting that emotional intelligence (EQ) may have a positive influence and a protective effect against depression, anxiety and burnout. 10,11,12,13,14 Therefore, our goal is to introduce the concept of $E Q$ and its possible positive effects in physicians' performance and wellness.

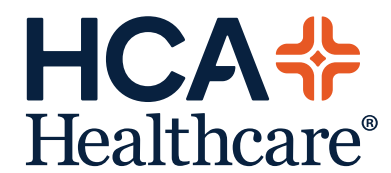

www.hcahealthcarejournal.com

(c) 2021 HCA Physician Services, Inc. d/b/a Emerald Medical Education
HCA Healthcare
Journal of Medicine 


\section{Understanding Burnout}

The diagnosis of burnout syndrome is made in the context of chronic, work-related stress. It results in a phenomenon of pathological human adaptation and the subsequent consequencesemotional fatigue, decreased efficacy or accomplishment and increased detachment from work or feelings of cynicism. ${ }^{15,16}$ The prevalence has been rising over the last few years, reaching critical levels. Rates above $50 \%$ have been documented in both physicians-in-training and practicing physicians. ${ }^{1,3,15,16,17}$ In 2014, a survey revealed that $54 \%$ of US physicians report having at least 1 symptom of this syndrome. ${ }^{2}$ Even more concerning, in 2018, a new survey indicated that $78 \%$ of physicians experience feelings of professional burnout at least sometimes. ${ }^{17}$

Burnout has been correlated with depression, increased odds of alcohol abuse, sleep disturbance, fatigue, marital and personal relationship disruption and a twofold increased risk of suicidal ideation. ${ }^{2,18}$ Rates of depression in physicians are more than double that in the general population. A recent meta-analysis has shown that up to $43 \%$ of residents and $30 \%$ of medical students have positive screening for depression or depressive symptoms during their training. ${ }^{19,20}$ In addition, approximately 400 physicians take their own lives on an annual basis. $^{21}$

\section{Physician Burnout and the Healthcare System}

Beyond the individual consequences of physician burnout, this condition affects the entirety of the healthcare system. ${ }^{2,15}$ There is a clear association between this syndrome and negative clinical outcomes, increased risk of patient safety incidents, medical errors and poorer quality of care due to low professionalism, unfavorable productivity and reduced patient satisfaction. Furthermore, burnout has been associated with $17 \%$ increased odds of being involved in a medical malpractice suit. ${ }^{15}$ In addition, burned-out physicians have higher absenteeism rates and are more likely to report an intention to reduce their work hours or stop practicing medicine. ${ }^{3} \mathrm{~A}$ recent study revealed that approximately $\$ 4.6$ billion in costs related to physician turnover and reduced clinical hours is attributable to burnout each year in the US. ${ }^{3}$
Based on the literature, the increased prevalence of physician's burnout seems to correlate with excessive workload and increasing non-patient-focused work such as working on electronic medical records (EHR). ${ }^{15}$ Data suggests that stressful aspects of physician traininglong hours, frequent shifts, making difficult decisions, feeling at risk for errors, learning to deal with death and estrangement from family-could increase the risk of depression and burnout. 16,21

\section{Initiatives for Reducing Burnout}

Many different strategies have been considered during the last few years to counteract burnout and its negative outcomes. The majority of these different approaches have focused on organizational changes and require many levels of institutional involvement and willingness. Reducing work hours and workload, implementing physician wellness activities, improving EHR usability and facilitating access to mental health counselling are some examples. ${ }^{6,15,17}$ In parallel, some more individualistic, evidence-based strategies such as mindfulness, stress management training, communication skills training and self-care efforts have been recommended. ${ }^{10,15,22,23}$ In the same context, there is consistent evidence that demonstrates physicians with high emotional intelligence $(E Q)$ and leadership skills can more easily reconcile the different challenges that contribute to burnout. ${ }^{24}$

\section{Introducing the Concept of Emotional Intelligence}

Emotional intelligence-"the ability to perceive emotion, integrate emotion to facilitate thought, understand emotions and regulate emotions to promote personal growth"14 consists of 5 categories: self-awareness, social awareness, motivation, empathy and self-regulation. ${ }^{13,24,25}$ In general, leadership and EQ are intimately connected, and it is described that the higher the level of emotional intelligence, the greater the leader development. Leaders with $E Q$ are considered more effective because of their ability to self-manage, listen, understand, build relationships, communicate and develop others. ${ }^{14}$ 


\section{Emotional Intelligence and Physician Performance}

Specifically, in medicine, physicians with higher $E Q$ are associated with longer careers, positive patient-physician interactions, increased empathy and improved communication skills.12,14 EQ enables physicians to provide optimal patient care and is also considered a predictor of success in residency training. 13,14,25

As an example, an interactive simulation $E Q$ training program for otolaryngologists demonstrated improvement of participants' recognition, understanding and management of their emotions followed by change of behaviors that increased patient satisfaction. ${ }^{25,26}$ In addition, a multi-institutional study, published in 2013, revealed that $E Q$ had a significant correlation with anesthesiology residents' performance assessed by the 6 core competencies of the Accreditation Council for Graduate Medical Education (ACGME): Patient Care, Medical Knowledge and Practice-Based Learning, Communication Skills, Practice- Based Learning, Systems-Based Practice. ${ }^{25}$

\section{Emotional Intelligence and Physician Well Being}

It has been described that $E Q$ may confer a protective effect against burnout and favors physician well-being, resilience and stress management.12,27 Contrary, a low EQ has been associated with less ability to cope with the stressors of medical training and practice. ${ }^{13}$ Indeed, for surgery residents, EQ significantly predicted well-being, depression, burnout and its specific components-emotional exhaustion and depersonalization..$^{27,28}$ In pediatric resident's, EQ training generated a significant improvement in stress management and overall wellness. ${ }^{27}$

A recent article, ${ }^{6}$ which discussed the benefits of emotional intelligence during the COVID-19 pandemic, suggested the use of mindfulness micro-practices as a method to prevent burnout. Indeed, there is some evidence that practicing diaphragmatic breathing, ${ }^{23}$ self-check while doing hand hygiene or writing a grateful diary may have a beneficial effect. ${ }^{10,22}$ Those simple activities that require minimal time to learn and implement seem to have the potential to build personal resources to successfully navigate the multiple challenges that physicians are dealing with, and the continuous and unexpected changes that healthcare providers experience in a daily basis. ${ }^{6}$

\section{Conclusions}

The gap between what is expected from physicians and the support and training that they are receiving is constantly increasing, and affecting the performance and quality of life of our healthcare providers., ${ }^{1,2,8}$ This is a new paradigm in medicine that needs to be promptly assessed and solved, as this situation is significantly affecting not only patients but also the complete healthcare system, including the same physicians and other health care providers. ${ }^{3}$ This complex situation has been accentuated even more during the current COVID pandemic. ${ }^{4,5,6,7}$

Considering the severity of the current situation and the hazardous implications of maintaining the status quo, it is imminent to consider a different, multidimensional, effective and more feasible long-term approach. While expecting prompt changes from our complex and multilayered healthcare system does not seem realistic, individual efforts towards selfcare and stress reduction strategies may not be sufficient.

Even though EQ has been favorably associated with wellness, decreasing burnout, better physician-patient relationships and better patient outcomes, ${ }^{12,25}$ there has not been any significant, unified or standardized movement towards integration into the medical school and residency curricula. ${ }^{24,25,29}$

While recognizing that there are still gaps in knowledge and paucity of scientific evidence, ${ }^{29}$ we still believe allocating more effort and resources to research, development and implementation of $E Q$ training programs has the potential to enrich the understanding of how to educate effective, well-rounded and resilient physicians.

\section{Acknowledgments}

The authors thank Dr. Joann Farrell Quinn, PhD, MBA, Associate Professor and Director of SELECT Competency Assessment at Morsani College of Medicine, for her valuable contribution and her kindness. 


\section{Conflicts of Interest}

The authors declare they have no conflicts of interest.

The authors are employees of Aventura Hospital and Medical Center, a hospital affiliated with the journal's publisher.

This research was supported (in whole or in part) by HCA Healthcare and/or an HCA Healthcare affiliated entity. The views expressed in this publication represent those of the author(s) and do not necessarily represent the official views of HCA Healthcare or any of its affiliated entities.

\section{Author Affiliations}

1. Aventura Hospital and Medical Center, Aventura, FL

\section{References}

1. Tawfik DS, Profit J, Morgenthaler TI, et al. Physician Burnout, Well-being, and Work Unit Safety Grades in Relationship to Reported Medical Errors. Mayo Clin Proc. 2018;93(11):1571-1580. https://doi.org/10.1016/j.mayocp.2018.05.014

2. Wright AA, Katz IT. Beyond Burnout - Redesigning Care to Restore Meaning and Sanity for Physicians. N Engl J Med. 2018;378(4):309-311. https://doi.org/10.1056/nejmp1716845

3. Han S, Shanafelt TD, Sinsky CA, et al. Estimating the Attributable Cost of Physician Burnout in the United States. Ann Intern Med. 2019;170(11):784-790. https://doi.org/10.7326/ m18-1422

4. Dewey C, Hingle S, Goelz E, Linzer M. Supporting Clinicians During the COVID-19 Pandemic. Ann Intern Med. 2020;172(11):752-753. https://doi. org/10.7326/m20-1033

5. Santarone K, McKenney M, Elkbuli A. Preserving mental health and resilience in frontline healthcare workers during COVID-19. Am J Emerg Med. 2020;38(7):1530-1531. https://doi.org/10.1016/j. ajem.2020.04.030

6. Fessell D, Cherniss C. Coronavirus Disease 2019 (COVID-19) and Beyond: Micropractices for Burnout Prevention and Emotional Wellness. J Am Coll Radiol. 2020;17(6):746-748. https://doi. org/10.1016/j.jacr.2020.03.013

7. Ripp J, Peccoralo L, Charney D. Attending to the Emotional Well-Being of the Health Care Workforce in a New York City Health System During the COVID-19 Pandemic. Acad Med. 2020;95(8):1136-1139. https://doi.org/10.1097/ acm.0000000000003414

8. Blumenthal DM, Bernard K, Bohnen J, Bohmer R. Addressing the leadership gap in medicine: residents' need for systematic leadership development training. Acad Med. 2012;87(4):513-522. https://doi.org/10.1097/acm.0b013e31824a0c47

9. Emanuel EJ, Gudbranson E. Does Medicine Overemphasize IQ?. JAMA. 2018;319(7):651-652. https://doi.org/10.1001/jama.2017.20141

10. Panagioti M, Panagopoulou E, Bower P, et al. Controlled Interventions to Reduce Burnout in Physicians: A Systematic Review and Meta-analysis. JAMA Intern Med. 2017;177(2):195-205. https://doi.org/10.1001/jamainternmed.2016.7674

11. Ward HB. Resident Leadership in the Era of COVID-19: Harnessing Emotional Intelligence. Acad Med. 2020;95(10):1521-1523. https://doi. org/10.1097/acm.0000000000003558

12. Arora S, Ashrafian H, Davis R, Athanasiou T, Darzi A, Sevdalis N. Emotional intelligence in medicine: a systematic review through the context of the ACGME competencies. Med Educ. 2010;44(8):749-764. https://doi.org/10.1111/j.13652923.2010.03709.x

13. Gorgas DL, Greenberger S, Bahner DP, Way DP. Teaching Emotional Intelligence: A Control Group Study of a Brief Educational Intervention for Emergency Medicine Residents. West J Emerg Med. 2015;16(6):899-906. https://doi. org/10.5811/westjem.2015.8.27304

14. Weng HC, Hung CM, Liu YT, et al. Associations between emotional intelligence and doctor burnout, job satisfaction and patient satisfaction. Med Educ. 2011;45(8):835-842. https://doi. org/10.1111/j.1365-2923.2011.03985.x

15. West CP, Dyrbye LN, Shanafelt TD. Physician burnout: contributors, consequences and solutions. J Intern Med. 2018;283(6):516-529. https:// doi.org/10.1111/joim.12752

16. Ishak WW, Lederer S, Mandili C, et al. Burnout during residency training: a literature review. J Grad Med Educ. 2009;1(2):236-242. https://doi. org/10.4300/jgme-d-09-00054.1

17. Jha AK, Iliff AR, Chaoui AA, Defossez S, et al. A Crisis in Health Care: A Call to Action on Physician Burnout. Massachusetts Medical Society; 2018. Accessed September 3, 2020. http:// www.massmed.org/News-and-Publications/ MMS-News-Releases/Physician-Burnout-Report-2018/

18. Gold KJ, Sen A, Schwenk TL. Details on suicide among US physicians: data from the National Violent Death Reporting System. Gen Hosp Psychiatry. 2013;35(1):45-49. https://doi.org/10.1016/j. genhosppsych.2012.08.005

19. Mata DA, Ramos MA, Bansal N, et al. Prevalence of Depression and Depressive Symptoms Among Resident Physicians: A Systematic Review and Meta-analysis. JAMA. 2015;314(22):23732383. https://doi.org/10.1001/jama.2015.15845

20. Rotenstein LS, Ramos MA, Torre M, et al. Prevalence of Depression, Depressive Symptoms, and Suicidal Ideation Among Medical Students: 
A Systematic Review and Meta-Analysis. JAMA. 2016;316(21):2214-2236. https://doi.org/10.1001/ jama.2016.17324

21. Andrew LB, Brenner BE. Physician suicide. Medscape. Updated August 01, 2018. Accessed September 3, 2020. https://emedicine.medscape. com/article/806779-overview.

22. Sexton JB, Adair KC. Forty-five good things: a prospective pilot study of the Three Good Things well-being intervention in the USA for healthcare worker emotional exhaustion, depression, work-life balance and happiness. BMJ Open. 2019;9(3):e022695. Published 2019 Mar 20. https://doi.org/10.1136/bmjopen-2018-022695

23. Hopper SI, Murray SL, Ferrara LR, Singleton JK. Effectiveness of diaphragmatic breathing for reducing physiological and psychological stress in adults: a quantitative systematic review. JBI Database System Rev Implement Rep. 2019;17(9):1855-1876. https://doi.org/10.11124/jbisrir-2017-003848

24. Uchino R, Yanagawa F, Weigand B, et al. Focus on emotional intelligence in medical education: From problem awareness to system-based solutions. Int J Acad Med. 2015;1(1):9-20. https://doi. org/10.4103/2455-5568.172703

25. Talarico JF, Varon AJ, Banks SE, et al. Emotional intelligence and the relationship to resident performance: a multi-institutional study. $J$ Clin Anesth. 2013;25(3):181-187. https://doi. org/10.1016/j.jclinane.2012.08.002

26. Dugan JW, Weatherly RA, Girod DA, Barber CE, Tsue TT. A longitudinal study of emotional intelligence training for otolaryngology residents and faculty. JAMA Otolaryngol Head Neck Surg. 2014;140(8):720-726. https://doi.org/10.1001/jamaoto.2014.1169

27. Shahid R, Stirling J, Adams W. Promoting wellness and stress management in residents through emotional intelligence training. Adv Med Educ Pract. 2018;9:681-686. Published 2018 Sep 20. https://doi.org/10.2147/amep.s175299

28. Cofer KD, Hollis RH, Goss L, Morris MS, Porterfield JR, Chu DI. Burnout is Associated With Emotional Intelligence but not Traditional Job Performance Measurements in Surgical Residents. J Surg Educ. 2018;75(5):1171-1179. https:// doi.org/10.1016/j.jsurg.2018.01.021

29. Frich JC, Brewster AL, Cherlin EJ, Bradley EH. Leadership development programs for physicians: a systematic review. J Gen Intern Med. 2015;30(5):656-674. https://doi.org/10.1007/ s11606-014-3141-1 